\title{
Study on the Geohazard Distribution Laws and Hazard-Causing Mechanism in Menghai County of Yunnan Province
}

\author{
Mingchang Hei' ${ }^{*}$, Xuegang Dai', Xukai Yuan', Jia Xiong², Xiaobo Kang3 \\ ${ }^{1}$ Faculty of Land Resources Engineering, Kunming University of Science and Technology, Kunming 650093, China \\ 2The Middle School Attached to Chongqing Normal University, Chongqing 4000142, China \\ ${ }^{3}$ Yunnan Institute of Geo-environmental Monitoring (Yunnan Research Institute of Environmental Geology), Kunming \\ 650216, China \\ *Corresponding author: Mingchang Hei, MingchangHei0816@163.com

\begin{abstract}
The study area is located at the southwest border of Yunnan Province and the southward extended part of Nushan Mountain, with complex and fragile geo-environmental conditions. Deep geological survey and mathematical analytical investigation on the geohazard distribution and hazard-causing mechanisms in this area were carried out in this study. The results revealed that: (1) The development of geohazards was affected differently by different slope shapes, slope structures and elevations; (2) Most of the geohazards were developed in medium shallow cut ridge-like medium-height mountainous geomorphological region and shallow cut steamed bun-like low and medium-height mountainous geomorphological region, and they were relatively concentrated on tectonic zones like fault zones; (3) The slopes formed by loose earth piling up on the surface of Indo-Chinese magmatic rock and Lancang Group metamorphic rock formations were most prone to slope instability and even landslide. The deep study on the geohazard distribution and hazard-causing mechanisms can provide geoscientific basis and reference for the prevention and mitigation work of geohazards under similar geo-environmental conditions.
\end{abstract}

Keywords: Menghai County; Geohazard; Distribution law; Hazard-causing mechanism

Publication date: September 2021; Online publication: September 30, 2021

\section{Introduction}

Located in Menghai County in the southwest of Yunnan Province, the study area adjoins Jinghong City in the east, Simao City in the northeast, and Lancang County in the northwest, and borders Burma in the southwest, with the border line of $146.6 \mathrm{~km}$ and total area of $5,511 \mathrm{~km}^{2}$, and the traffic conditions are quite convenient in the area. Besides, the study area is featured by intense terrain cutting, diversified formation lithologies and complex geological structures. With the continuous expansion and accelerated development, the geo-environmental conditions in this study area have been considerably changed: Free faces are generated due to mining; the gangue stacking in gullies has aggravated the risks; the slope stability is degraded owing to the mountain excavation; the site leveling and supporting are ineffective; the waste slags produced by engineering construction are arbitrarily piled up; the gully bank reconstruction in reservoirs induces instable bank slopes; geohazards are induced by the ditch leakage, all of which directly harm the life and property safety of ethnic minorities at border and restrict the local economic development. There is almost no cognition or study regarding single hazard-bearing body and region in this study area at present. Hence, it is urgent and necessary to study the spatial distribution of geohazards in the study area and analyze the hazard-causing laws. In recent years, the author has participated in the detailed investigation work on 
geohazards in this area at a scale proportion of 1:50,000. This professional investigation was implemented through point-line-surface combination. The "3S" new technology was actively utilized to guide the ground investigation work based on the remote sensing survey results. A total of 593 settlements, 31 mines and 29 schools in mountainous areas were investigated, the remote sensing interpretation covered $5,451 \mathrm{~km}^{2}$, the 1:50,000 measurement (isometric projection) of geohazards was $826.65 \mathrm{~km}^{2}$, and the engineering geological profile survey involved $10.23 \mathrm{~km}$. By combining the geohazards taking place in this area in recent years as well as the related checking and inspection results, the spatial distribution of geohazards in the study area and hazard-causing laws were expounded and explored in detail from the aspects of topography and landform, geological structure, formation lithology, etc. The deep study on the distribution of geohazards in the study area and hazard-causing laws can provide geoscience basis and reference for the hazard prevention and mitigation work, such as local (adjacent counties included) geohazard control, relocation and site selection for the poverty alleviation in different places and site selection for engineering construction $^{[1-3]}$.

\section{Geo-environmental Background of the Study Area}

The study area, which is seated on the south segment of longitudinal valley of Hengduan Mountains, is a southward extended part of Nushan Mountains. It is high in the northwest and low in the southeast, high and steep at the perimeter and gentle in the middle, and mountain peaks, hills and flat dams are mutually staggered. In the area, the highest altitude is 2,429 $\mathrm{m}$ (mean peak of Huazhuliangzi), boasting the first high peak within the prefecture; the lowest point is located at the intersection between Nanju River and Nanlan River, with the altitude of $535 \mathrm{~m}$ and relative altitude difference of $1,894 \mathrm{~m}$; the exposed strata in the study area, from new to old, are mainly Quaternary system, Cretaceous system, Jurassic system, Triassic system, Permian system, Carboniferous system and upper Proterozoic Lancang Group, and the dominant lithologies are hard-soft rock masses like sandstone, mudstone, tuff, andesite, granite, rhyolite and schist; the study area is situated at the south segment of Changning-Lancang fold belt, which is the southward extended part of Sanjiang fold system, the geotectonic structure here is an eugeosyncline fold belt that presents long-term polycyclic development, the third-order tectonic unit belongs to new Yingpan-Mengman median uplift, the main tectonic line approximately follows the south-north direction, which is basically identical with the direction of strata, being an arc that bulges eastward. The northwest press-twist faults play a dominant role in the study area, and the deep major fault of Lancang River has obvious abnormalities according to the aeromagnetic map and gravity survey. It is speculated that the fault depth reaches the Si-Mg layer, which is referred to the suture line between Indian Plate and Eurasian Plate. Moreover, affected by the obduction and uplift of Eurasian Plate, the structure line is mainly manifested by the intermittent upward motion and fault activity between crustal plates, frequent seismic activities, widely distributed geothermal hot springs, etc. Under the influence of regional tectonic activities, the rock structure is loose and broken in the study area, with low mechanical strength and obvious weathering differences (the thickness of completely weathered zone can reach $15 \mathrm{~m}$ ). Spheroidal weathering takes place in the granite zone, and the unfavorable rock association and groundwater infiltration provide favorable conditions for the occurrence of geohazards [4].

\section{Current Geohazard Status in the Study Area}

Geohazards are developed at 159 places in the study area, including three geohazard types: landslide, collapse and debris flow ${ }^{[4]}$. Landslide occurs at 149 places, accounting for $93.7 \%$ of total number of geohazards, debris flow at 9 places $(5.66 \%)$ and collapse at 1 place $(0.63 \%)$.

According to the substance and structure, landslide is divided into three types: collapsing accumulation body landslide, diluvial-residual landslide and rock landslide, where small-scale shallow earth landslide, 
the "chain effect" of this geohazard is apparent ${ }^{[5]}$. Landslide stability is divided into three levels: stable, relatively stable and unstable, and nowadays, most landslides are under unstable state. The debris flow developing in the study area is mainly small-scale debris flow. According to the drainage basin form, debris flow is divided into gully-type debris flow and slope surface-type debris flow, where the former plays a dominant role, characterized by "long gully, large catchment area, water flow throughout the year, distinct three zones and steep bank slope." The latter is featured by "small scale, great vegetation destruction, strong surface erosion, distinct three zones, steep bank slope and no obvious circulation area." There are five debris flows at the development stage and four ones at vigorous stage, and low-susceptibility debris flows are in the majority; one collapse geohazard point is developed in granite strata of the study area. To be specific, the differentially weathered block (rolling) stones go through instability and form dangerous rock masses because the completely weathered sandy soil beneath the stones are scoured by the water flow on the slope surface formed by rainfalls. The differentially weathered dangerous rock masses, which vary in lumpiness, are located on steep slope. As the slope is unstable, the dangerous rock masses are susceptible to instability and tumbling under the actions of rainfall, earthquake, blast vibration, weathering and unloading ${ }^{[6-7]}$.

\section{Geohazards Distribution and Hazard-Causing Laws in the Study Area}

The study area is quite developed with geohazards, with totally 159 points exposed to geohazards and hidden dangers. The geohazards are distributed in six towns, five villages and a farm. Mengsong Village and Xiding Village include the most geohazard points, with 38 and 34 geohazard points, respectively, followed by Daluo Town, Blang Mountain Blang Nationality Village and Glang \& Hani Nationality Village, with 19, 17 and 16 geohazard points, respectively. The number of geohazard points distributed in other villages and towns is small $(<10)$. The geohazards present overall nonuniform spatial distribution and local concentrated distribution.

Landslide is a prevailing geohazard in the study area, followed by debris flow. With the enhancement of human engineering activities in recent years, the geohazards show an ever-increasing trend. The geohazards mostly take place in multiple processes, during which one geohazard can trigger the occurrence and development of another or several disasters, thus forming a geohazard chain. In the study area, the number of geohazards presents a growth trend owing to the socioeconomic development, increasing human engineering activities and frequent disastrous weather in recent years. Rainfall is an important factor inducing the geohazards, and thus geohazards occurred frequently at May to October in each year in the study area, and the annual occurrence and development of geohazards is of evident seasonality ${ }^{[8-10]}$.

\subsection{Topographic conditions and geohazards}

\subsubsection{Geomorphic units and geohazards}

Different geomorphic units represent different altitudes and cutting depths as well as different geological agent and groundwater runoff conditions like weathering, denudation and erosion, which are the direct manifestations of tectonic and lithological differences and objectively decide the significant differences of slope engineering geological characteristics ${ }^{[8]}$. Located at the south of Yunnan Province and southward extended part of Nushan Mountains, the study area is cut by rivers like Lancang River, Nanlan River, Liusha River, Nanguo River and Mengwang River, and most gullies are developed in "V" shape. It is high in the northwest and low in the southeast, high and steep at the perimeter and gentle in the middle, and mountain peaks, hills and flat dams are mutually staggered. The mountainous areas account for $93.45 \%$ and dam areas account for $6.55 \%$. According to the genetic type, the landform in the whole area can be divided into tectonic erosion, tectonic denudation and depositional landform. Through analytically studying the 159 geohazards, 71 geohazards are located within medium shallow cut ridge-like medium-height mountainous 
geomorphological region and 43 ones occur in shallow cut steamed bun-like low and medium-height mountainous geomorphological region, while others are sporadically distributed in other geomorphological regions (Figure 1. and Figure 2.), and the geohazard development density is the maximum in the medium shallow cut ridge-like medium-height mountainous geomorphological region. Hence, the topographic and landform features provide advantageous spatial conditions for the generation of geohazards and decide the necessity of geohazard development.

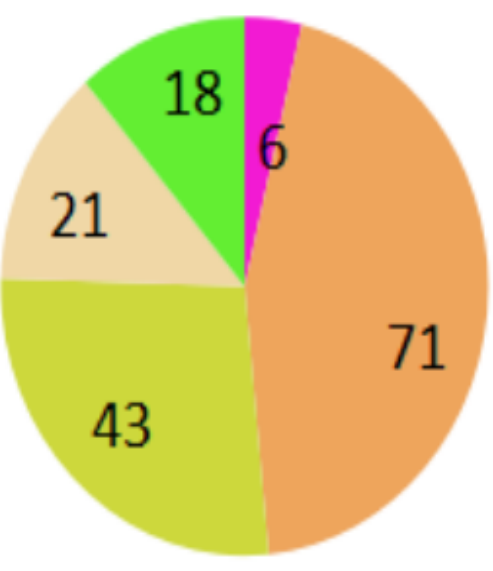

Medium cut single-ridge like medium-height mountainous landform

Medium shallow cut ridge-like medium-height mountainous landform

Shallow cut steamed bun-like low and medium-height mountainous landform

Micro-cut hummock-like low-height and low and medium-height mountainous landform

Basin and fluviatile deposit landform

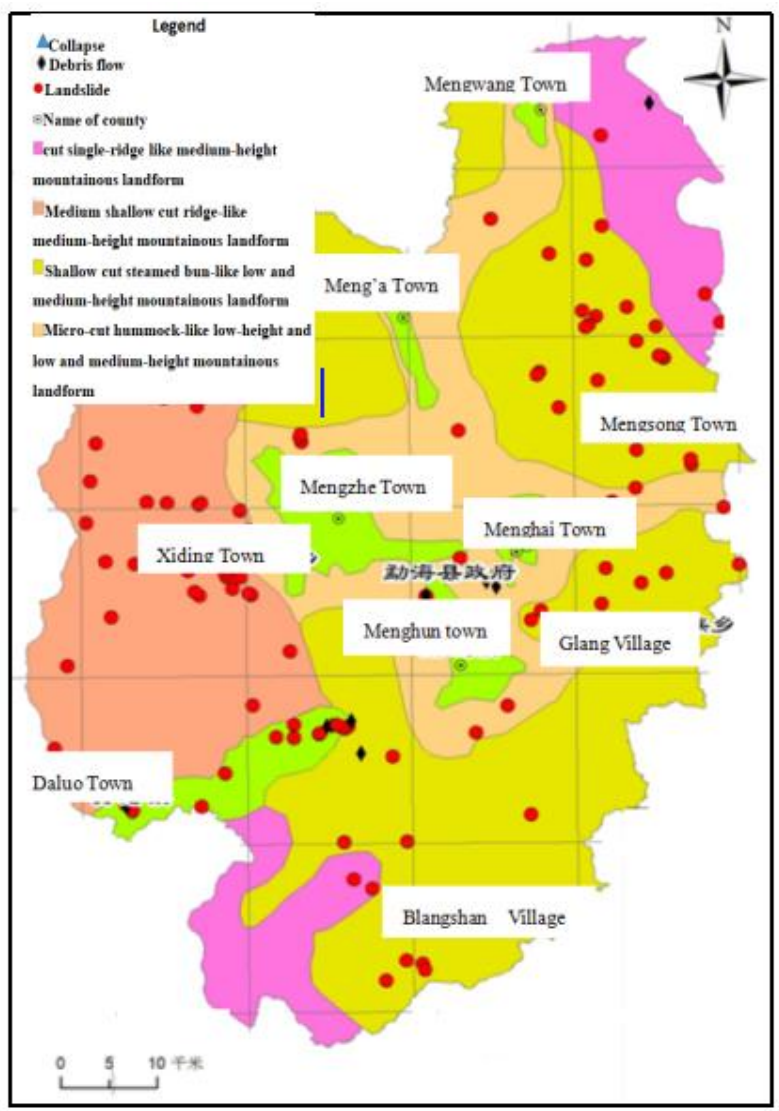

Figure 1. Numbers of geohazards developed in Figure 2. Geohazard development and different geomorphological regions distribution map of different geomorphological regions in the study area

\subsubsection{Topographic slope and geohazards}

Most of the 149 landslides analyzed in this study take place within the topographic slope of $20-40^{\circ}$, where there are totally 124 landslide points, accounting for $83.22 \%$ of total number of landslides (as shown in Figure 3.). Among the nine debris flows, there is only one slope surface-type debris flow, while the other eight ones belong to gully-type debris flows, which are all developed within the average longitudinal slope of 100-300\% of main gully. Hence, the topographic slope has a great bearing on the generation of landslide and collapse, and the landslide distribution in the study area is obviously controlled by the topographic slope.

\subsubsection{Slope forms and geohazards}

In the study area, the slope forms are divided into concave slope, straight slope, convex slope and step slope according to the different micro-landforms formed at adaptive crust uplift speed and undercut speed of hydrological network. Among the 149 landslides developed in the study area, 66 ones are generated in concave slopes, accounting for 44.30\%; 44 ones in straight slopes (29.53\%); 33 ones in convex slopes $(22.15 \%)$; six ones in step slopes (4.03\%) (as shown in Figure 4.). Besides, it is worth mentioning that 
following the generation of landslide, concave slopes will mostly be formed on some slope forms, which will form new unstable slopes and generate new landslides under the effects of water flow and loading.

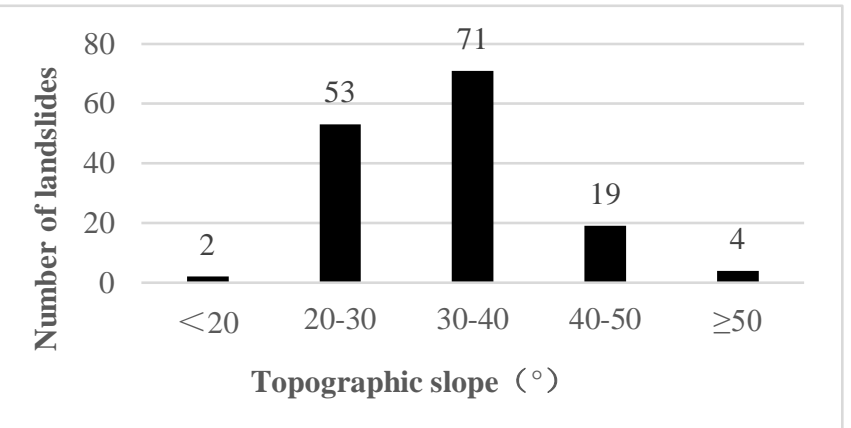

Figure 3: Statistical Graph of Landslide Development at Different Slopes

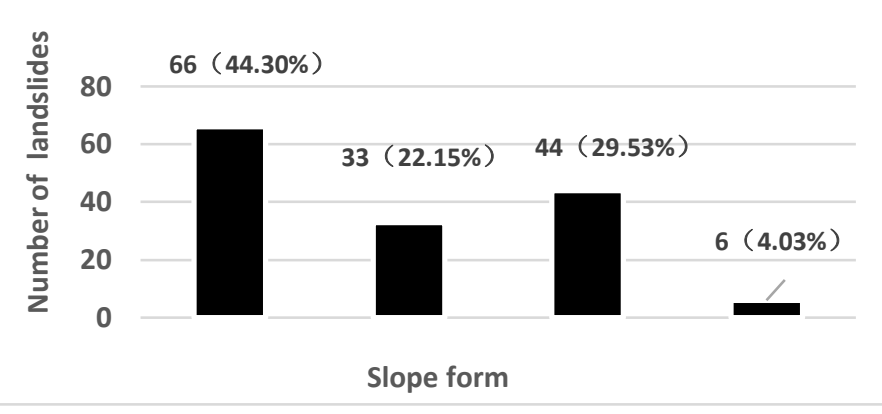

Figure 4: Statistical Graph of Landslide Development with Different Slope Forms

\subsubsection{Slope structures}

According to the original slope structure type, the slopes in the study area are divided into four types: dip slope, oblique crossing slope, reverse slope and specially structured slope. Among the 149 landslides, 23 ones are developed in dip slopes, accounting for $15.44 \%$; 25 ones in oblique crossing slopes (16.78\%); 15 ones in reverse slopes (10.07\%); 86 ones in specially structured slopes $(57.72 \%)$.

\subsection{Distribution elevation and geohazards}

By analyzing the elevations of 149 landslides and one collapse in the study area, it is discovered that 12 geohazards are developed below the elevation of $800 \mathrm{~m}$, accounting for $8.00 \%$ of total number of geohazards; 12 within the elevation of 800-1,000 m (8.00\%); 17 ones within the elevation of 1,000-1,200 $\mathrm{m}(11.33 \%) ; 27$ ones within the elevation of 1,200-1,400 $\mathrm{mm}(18.00 \%)$; 38 ones within the elevation of 1,400-1,600 $\mathrm{m}(25.53 \%) ; 42$ ones within the elevation of 1,600-1,800 $\mathrm{m}$ (28.00\%); two ones above the elevation of $1,800 \mathrm{~m}(1.33 \%)$. The area with relatively concentrated development of geohazards in the study area has the elevation of 1,200-1,800 m, at which the geohazards are developed most.

\subsection{Geological structure and geohazards}

The study area is situated at the south segment of Changning-Lancang fold belt, which is the southward extended part of Sanjiang fold system, and the main tectonic line nearly follows the south-north direction, which is basically consistent with the direction of strata. Under the tectonic influence, the bedrocks in the area experience folding and breakage. Moreover, given the local unique climatic conditions, the surface rocks are intensely affected by the physical weathering, so the rock and earth masses are of poor engineering properties, and the geohazards are mostly developed in a straight and banding-like distribution, which basically keeps consistent direction with the tectonic line. In the study area, the formation of tectonic zones like Lange Fault, Paliang-Longdao Fault, Manzhan Fault, Jieliang Fault and Manmeidui Fault is accompanied by the development of a large number of secondary faults, thus forming various rock mass structural surfaces with different scales. Besides, characteristic landforms like anticlinal mountains and synclinal valleys, which are greatly different, are formed, and the axial part and hinge zone of folds are especially the areas with the most concentrated tectonic stress, which contribute a lot to the geohazard development. Based on the analysis results through the spatial superposition of geohazard points and geological structures within the buffer zone range of $500 \mathrm{~m}$, the geological structures are correlated with geohazards to some extent. In general, the areas with complex geological structures have poorer 
environmental disturbance resistance and poorer stability, leading to a higher occurrence probability of geohazards. According to the analytical investigation, a total of 30 geohazards and hidden dangers are located at or nearby faults, accounting for $18.87 \%$ of total number. The geohazards present a relatively concentrated distribution on tectonic zones like Mange Fault, Paliang-Longdao Fault, Manzhan Fault, Jieliang Fault and Manmeidui Fault.

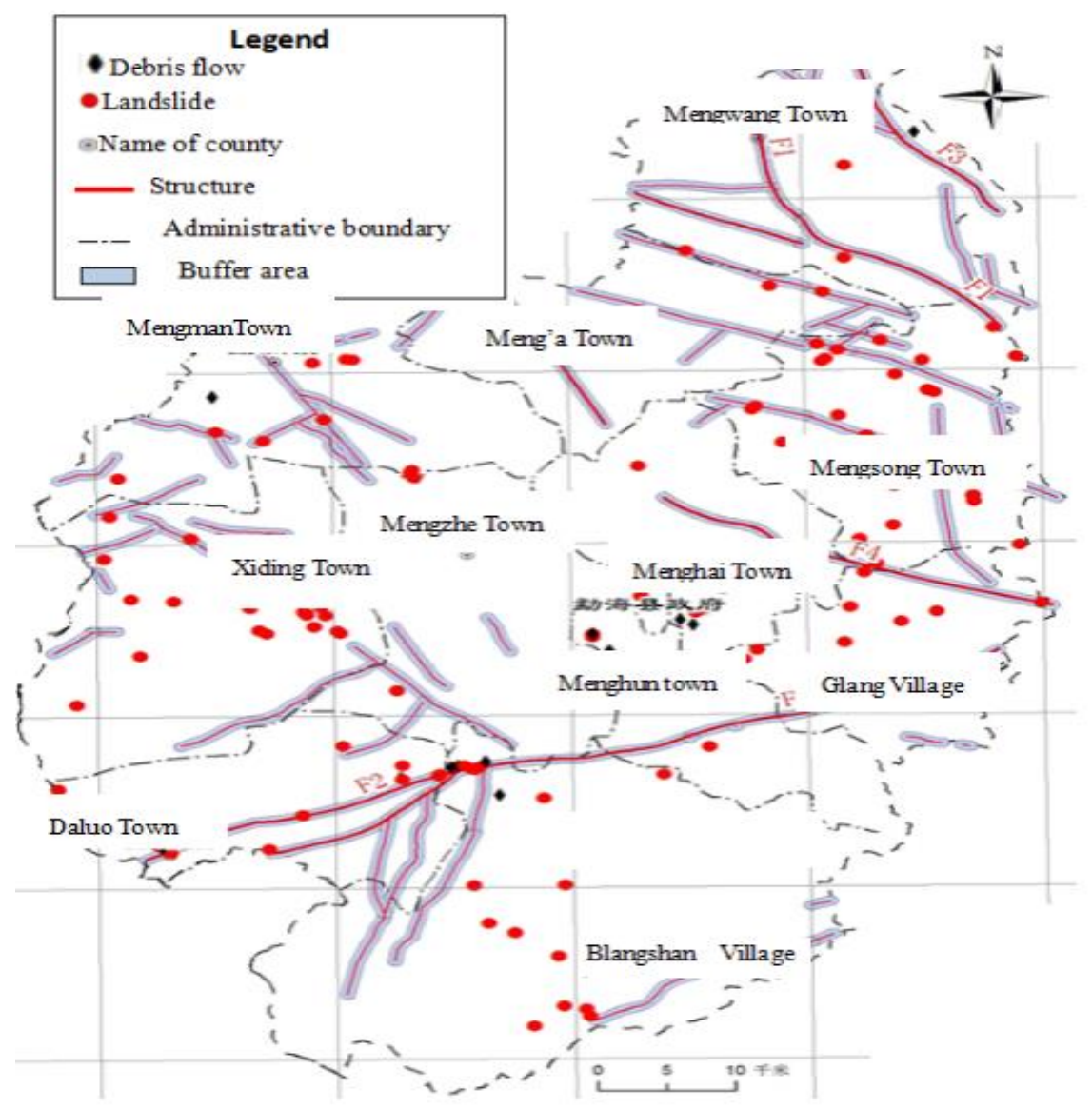

Figure 5. Distribution Map of Rock and Soil Mass Types and Geohazards

\subsection{Rock and soil mass structure types and geohazards}

Different lithologies are mutually associated in the study area, constituting stratiform soft-relatively hard rock formations, where soft rocks can be easily weathered in the rock formations to form weak structural planes. The rock masses are featured by joint development, broken structure and easy weathering, and the adverse rock association and groundwater infiltration provide advantageous conditions for the occurrence of geohazards like landslide and collapse. Influenced by the differential weathering, the outcropping rocks are broken into pieces after weathering, which provides the material source for debris flow ${ }^{[8]}$. By analyzing the landslide development status in the area, it can be obtained that loose soil mass is the slope that is most beneficial for generating landslides, and it is especially susceptible to slope instability when the dip angle of contact surface between loose soil mass and underlying bedrocks is smaller than the topographic slope and greater than $25^{\circ}$ under the intense undercutting action of gullies. With landslide taken for example, most landslides in the study area take place in magmatic rock formations and surface cover layer of metamorphic rock strata in Lancang Group, where they are mostly developed in magmatic rock formations at 55 places, accounting for $36.91 \%$ of total number of landslides, followed by those occurring in 
metamorphic rock formations in Lancang Group (55, 36.91\%). Only 14 landslides happen in the surface cover layer of other strata, accounting for $9.40 \%$ of total number of landslides. Hence, the rock and soil masses in the study area constitute the material basis for the generation of geohazards, and their types, properties and characteristics exert important effects on the geohazard development, as shown in Figure 5.

\subsection{Human engineering activities and geohazards}

According to the analytical investigation, a total of 82 landslides are directly caused by human engineering activities, accounting for $55.03 \%$ of total number of landslides. These landslides, which are relatively concentrated, are mainly distributed around houses and engineering construction areas like along highways, mines and rivers, mainly in the following forms: (1) Village and town construction, slope cutting and excavation can generate high and steep slopes and trigger geohazards like landslide and collapse. Ancient landslides experience deformation and revival to different extents because houses are built on their accumulation bodies. (2) Mining activities result in the silting river valleys and even debris flow, which generates a great impact on the downstream ecological environment and threatens highways, fields and private houses. (3) Highway construction, mountain excavation and stone prying and loose rock masses destruct the slope stability and provide rich loose solid matters for debris flows. (4) The cultivation on steep slopes and unreasonable predatory land exploitation and utilization lead to the geo-environmental deterioration and ecological changes and trigger all kinds of geohazards. The aforementioned human activities that are inharmonious with the ecological environment have changed or affected the surface runoff characteristics, accompanied by the phenomena of "mountain peeling" (rapid and disastrous slope surface erosion) + "rill cutting" (rill erosion) + "river wandering" (riverbed silts up and rises, and the lateral erosion effect of river is strengthened) + "bridge and culvert silting" (flood water carrying branches and grass block the bridge and culvert) + "flooding", all of which will finally give rise to geohazards like landslide and debris flow.

\section{Conclusions}

(1) There are mainly three geohazard types in the study area: landslide, debris flow and collapse, which are under the nonuniform spatial distribution and local concentrated distribution. The temporal distribution has the law of concentration, intensification, periodicity and continuous occurrence. The slope forms include straight slope, convex slope and $20-40^{\circ}$ slope, and the slope structures include specially structured slope and oblique crossing slope, while the geohazards are developed most in the landforms with the elevation of 1,200-1,800 m; the geohazard development density is the maximum in the medium shallow cut ridge-like medium-height mountainous geomorphological region.

(2) By analyzing the $500 \mathrm{~m}$ range of the buffer area, it is found that the areas with complex geological structures are featured by poor environmental disturbance resistance and poor stability, which increases the occurrence probability of geohazards. The geohazards are mainly concentrated on tectonic zones like Mange Fault, Paliang-Longdao Fault, Manzhan Fault, Jieliang Fault and Manmeidui Fault.

(3) The surface slopes in Indo-Chinese magmatic rock and Lancang Group metamorphic rock formations in the study area tend mostly to generate the slope stability, and even go through landslides when the dip angle of contact surface between loose soil mass and underlying bedrocks is smaller than the topographic slope and greater than $25^{\circ}$ under the intense undercutting action of gullies. In the study area, the geohazards induced by human engineering activities grow year by year. Human activities, which have become an important geological agent, are the most dynamic factor inducing the geohazards.

\section{Acknowledgements}

The study results of this paper have been achieved through the joint hard work of all members in the project 
team. The members participating in the field investigation project also include $\mathrm{Lu} \mathrm{H}$, Cao Y, Cao J, Wang Y Y, Huang X Z, Zhang W Y and Zhang G E, all of whom have provided reliable and detailed first-hand field information for writing this paper, and to whom we would like to extent our sincere gratitude! We would also like to thank the reviewers for scrutinizing the whole paper and giving the valuable opinions on the revision.

\section{Disclosure statement}

The author declares no conflict of interest.

\section{References}

[1] Zhang J, Kang XB, Lu H, et al., 2018, Study on Spatial Distribution of Geological Disasters in Middle Part of Ailao Mountain: A Case of Yuanjiang County. Journal of Engineering Geology, 26(03): 720-731.

[2] Bai YJ, Li MH, Wang DH et al., 2014, Characteristics and Disastrous Rule Research of Geohazards in Batang County, the Middle Reaches of Jinsha River. The Chinese Journal of Geological Hazard and Control, 25(02): 103-109.

[3] Li CY, Meng H, Zhang RL, Li YM, 2017, Risk Assessment of Geo-Hazard of China in County Unit. Hydrogeology \& Engineering Geology, 44(02): 160-166.

[4] Kang XB, Cao J, Hei MC, et al., 2017, Detailed Investigation Report on Geological Disasters in Menghai County, Yunnan Province. Kunming: Yunnan Institute of Geo-environmental Monitoring.

[5] Wu FQ, Lan HX, 2016, International Research Status and Frontiers on Engineering Geology and The Environment: A Review on IAEG XII congress. Journal of Engineering Geology, 24(01): 116129.

[6] Huang RQ, Qi SW, 2017, Engineering Geology: Review and Prospect of Past Ten Years in China. Journal of Engineering Geology, 25(02): 257-276.

[7] Guan FJ, Shen WZ, 2016, Study on Situation Analysis and Prevention of Geological Disasters in China. Hydrogeology \& Engineering Geology, 43(02): 7-10.

[8] Zhao SS, 2016, Study on Formation Mechanism and Dangerousness Zoning of Geological Disasters in Eryuan County, Yunnan Province. China University of Geosciences (Beijing).

[9] Fu HX, 2017, Development Characteristics and Preventive and Control Countermeasures of Geological Disasters in Mountainous Regions of Pu'er City. Yunnan Water Power, 33(03): $32-$ $34+60$.

[10] Qi Q, 2012, Evaluation Research on the Susceptibility Degree of Geological Disasters in Yuanyang County based on GIS and Hierarchy of Objectives Combined Analysis Method. China University of Geosciences (Beijing).

[11] Xiong DQ, 2009, A Study on Emergency Investigation and Hazard Assessment of 5.12 Wenchuan Earthquake Triggered Geological Hazards in Li County. Chengdu University of Technology. 